\title{
Mass spectral and theoretical studies on the tautomerism of selected thioesters
}

\author{
Patricia E. Allegretti ${ }^{1}$, Daniel Asens ${ }^{1}$, María de las Mercedes Schiavoni ${ }^{1}$, Rodolfo D. \\ Bravo $^{1}$, Eduardo A. Castro, ${ }^{2}$ and Jorge J. P. Furlong ${ }^{1}$ \\ ${ }^{1}$ Laboratorio de Estudio de Compuestos Orgánicos (LADECOR), División Química Orgánica, \\ Departamento de Química, Facultad de Ciencias Exactas, Universidad Nacional de La Plata, \\ (1900) La Plata, Buenos Aires, Argentina \\ ${ }^{2}$ INIFTA (UNLP-CONICET-CIC), Departamento de Química, Facultad de Ciencias Exactas, \\ Universidad Nacional de La Plata, Diagonal 113 y 64, Suc.4, C. C. 16, (1900) La Plata, Buenos \\ Aires, Argentina \\ E-mail: dirección@inifta.unlp.edu.ar/jubert@arnet.com.ar \\ (received 01 Nov 03; accepted 04 Feb 04; published on the web 10 Feb 04)
}

\begin{abstract}
Among carbonyl compounds esters are not usually involved in tautomeric equilibrium with the exception of $\beta$-ketoesters and thioesters. We show that mass spectrometry data are helpful in demonstrating the occurrence of the enol structure for thioesters, particularly significant for the dithio analogues. AM1 semiempirical MO calculations are also consistent with the experimental results.
\end{abstract}

Keywords: Tautomerism, thioesters, mass spectrometry, AM1 theoretical calculations

\section{Introduction}

The carbonyl-enol equilibrium is one of the oldest and most studied topics in physical organic chemistry and it is important in organic synthesis and to many biological processes ${ }^{1}$. The carbonyl-enol equilibrium constants are generally very low for carbonyl compounds which do not carry strong electron-withdrawing groups or conjugating substituents ${ }^{1-4} \cdot \mathrm{pK}$ Enol values are much lower for enols with $\beta$-electron-withdrawing groups, such as $\mathrm{C}=\mathrm{O}$ and the enol form is frequently observable. Many enols substituted with bulky aryl groups are also stable and currently happening and they display low pKenol values ${ }^{4}$.

The tautomerization equilibrium shows an interesting behavioral change for the sulfur analogues. Due to the lower stability of the thiocarbonyl $(\mathrm{C}=\mathrm{S})$ compared with the $\mathrm{C}=\mathrm{O}$ group ${ }^{5}$, thiocarbonyl derivatives having $\alpha$-hydrogens have a greater tendency to tautomerize ${ }^{6}$. In fact, 
enolization vs thioenolization of thioesters and thioxoketones has been studied and the effect of the heteroatom has been demonstrated ${ }^{5,7-10}$.

In contrast to thiones and 1,3-dithiodicarbonyl compounds, simple thionoesters and dithioesters are stable in the thione form. Evidently the thione-enethiol equilibrium does not seem to occur. Notwithstanding the thione is transformed by a base to the enethiolate anion (equation 1).

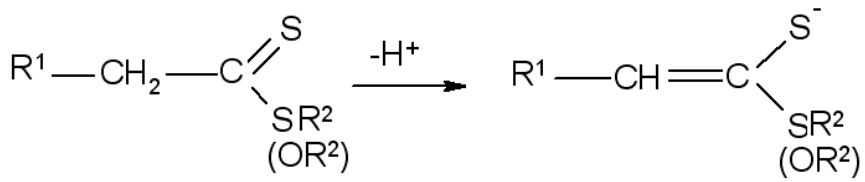

Thionocarbonic esters and dithiocarbonic esters are easily available ${ }^{11-16}$ and they are of special interest because the ester group reacts under very mild conditions and often without addition of a catalyst, giving condensation reactions or thioacylations.

In a general study of $\beta$-ketodithio acids by n.m.r. and i.r. spectroscopy ${ }^{17}$, a real keto-enol equilibrium was found just as in the oxygen series (equation 2).

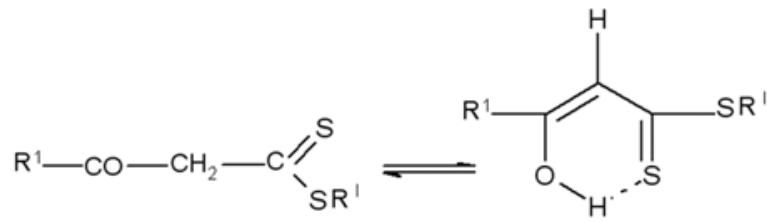

Diphenylthioacetic acid esters have been described as enethiols with no tautomeric equilibrium being detectable, although rearrangement to the thione form occurs in non-polar solvents ${ }^{18}$ (equation 3 ).<smiles>[R]OC(S)=C(c1ccccc1)c1ccccc1</smiles>

Due to the possibility of existence in both tautomeric forms, that is, as thione or thiol, mercaptothiophenes and related compounds are of special interest in this connection, too (equation 4).

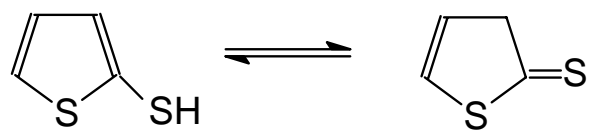

A thorough investigation of their n.m.r. and i.r. spectra has shown that these compounds exist solely in the thiol form, where the thiolene-2-ones exist exclusively in the ketone form ${ }^{19-22}$. To 
the best of our knowledge, at present there is no indication of thione-enethiol equilibria for esters. The present work resorts to mass spectrometry technique to examine the occurrence of tautomerization for selected esters and their sulfur analogues.

On the other hand, systematic and highly reliable theoretical calculations have been reported on the energy differences of many thiocarbonyl-thioenol systems and they have been compared them with those of the parent selenium and tellurium analogues ${ }^{23}$. This same approach is used here to give theoretical support to the experimental data.

\section{Experimental Section}

\section{Synthesis of Thioesters}

Non-commercially available compounds were synthesized and purified according to standard well known procedures ${ }^{24-26}$.

\section{Gas Chromatography-Mass Spectrometry}

These determinations were done by injection of methanol solutions $(1 \mu \mathrm{l})$ in an HP 5890 Series II Plus chromatograph coupled to an HP 5972 A mass spectrometric detector under the following conditions:

Column: HP5-MS, $30 \mathrm{~m}$ x $0.25 \mathrm{~mm}$ x $5 \mu \mathrm{m}$.

Carrier gas: Helium.

Injector temperature: $200^{\circ} \mathrm{C}$.

Oven temperature: $80^{\circ} \mathrm{C}, 10^{\circ} \mathrm{C} / \mathrm{min}, 200^{\circ} \mathrm{C}$.

Interface temperature: $300^{\circ} \mathrm{C}$.

Ion source temperature: $185^{\circ} \mathrm{C}$.

The pressure in the mass spectrometer, $10^{-5}$ torr, precludes ion-molecule reactions.

Electron energy: $70 \mathrm{eV}$.

\section{Computational Procedure}

Theoretical AM1 semiempirical calculations were performed using the standard HYPERCHEM ${ }^{\circledR}$ package $^{27}$. Since we resorted to heat of formation values in order to rationalize experimental findings and the AM1 technique has been especially parameterized to reproduce this sort of experimental data, we deem this choice is a sensible one for the molecular set under study. 


\section{Results and Discussion}

\section{Gas Chromatography-Mass Spectrometry}

Table 1 shows the most relevant mass spectral data for selected thioesters. For a better correlation the reported data are calculated according to the following ratio:

\section{$10^{3}$ Ion Abundance / $\Sigma$ Total Ion Abundance}

To weigh the occurrence of both tautomers in equilibrium (equation 5), suitable fragmentations have been assigned to the keto and enol forms. The loss of $\mathrm{XH}$ from the molecular ion could be assigned to the enol form and the $\mathrm{CH}_{2} \mathrm{R}^{1}$ radical loss to the keto form.

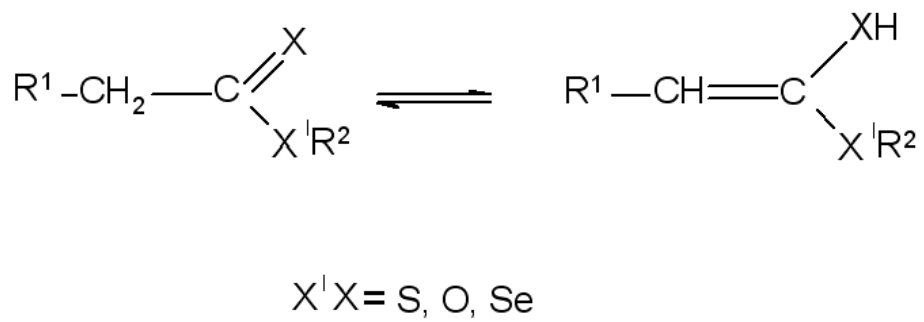

Despite the fact that the analyses have been carried out by GC-MS, no chromatographic separation has been observed so that the mass spectra are the result of the mix of both tautomers. By way of contrast, previous work reported chromatographic separation of the tautomeric forms for $\beta$-ketoesters ${ }^{28}$.

For compounds 1 and 2 the $(\mathrm{M}-\mathrm{XH})^{+} /\left(\mathrm{M}-\mathrm{CH}_{2} \mathrm{R}^{1}\right)^{+}$ratio does not apply since the methyl loss can also be explained from the enol tautomer by ionization of the $\mathrm{sp}^{3}$ heteroatom. Analogously, for compounds 11 and 12, the ethyl loss can be explained from both tautomers (equation 6 shows this fragmentation from the enol structure). This means that the ratio value should be higher in absence of this interference.

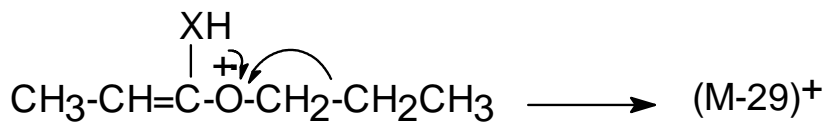

Additionally, for compounds 3-8, the radical loss $\left(\mathrm{M}-\mathrm{CH}_{2} \mathrm{R}^{1}\right)^{+}$could be justified from the enol structure by the following mechanism: 


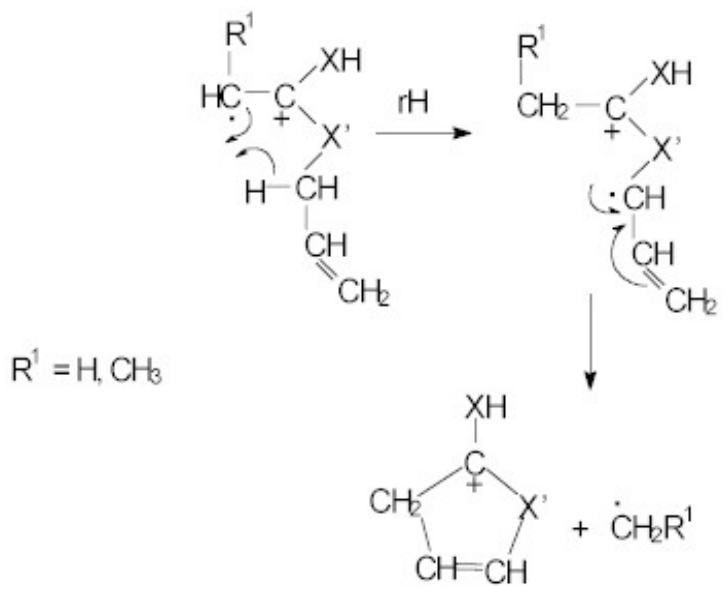

Table 1. Relevant mass spectral data for selected esters

\begin{tabular}{|c|c|c|c|c|}
\hline Compound & $\mathbf{M}^{+\cdot}$ & $(\mathrm{M}-\mathrm{XH})^{+}$ & $\left(\mathbf{M}-\mathrm{CH}_{2} \mathbf{R}^{1}\right)^{+}$ & $(\mathbf{M}-\mathrm{XH})^{+} /\left(\mathbf{M}-\mathrm{CH}_{2} \mathrm{R}^{1}\right)^{+}$ \\
\hline 1. Ethylacetate & 16.7 & - & 17.6 & 0 \\
\hline 2. Ethyldithioacetate & 109 & 1.1 & 0.98 & 1.1 \\
\hline 3. Allylacetate & 0.49 & - & 0.98 & 0 \\
\hline 4. Allyldithioacetate & 56.8 & 17.0 & 118 & 0.14 \\
\hline 5. Allylpropanoate & 1.1 & - & 3.2 & 0 \\
\hline 6. Allyldithiopropanoate & 58.4 & 9.8 & - & - \\
\hline 7.1-Methylallyldithiopropanoate & 98.4 & 14.6 & 73.0 & 0.2 \\
\hline 8. 3-Methylallyldithiopropanoate & 92.7 & 12.0 & 60.0 & 0.2 \\
\hline 9. Ethylphenylacetate & 192 & - & 162 & 0 \\
\hline 10. O-Ethylphenylthioacetate & 229 & 1.8 & 1.3 & 1.4 \\
\hline 11. Propylpropanoate & - & - & 45.9 & 0 \\
\hline 12. O-Propylthiopropanoate & - & 1.6 & 3.0 & 0.4 \\
\hline 13. Methylbutanoate & 6.9 & - & 43.1 & 0 \\
\hline 14. Methyldithiobutanoate & 113 & 1.1 & 0.4 & 2.75 \\
\hline 15. Methylpentanoate & 0.8 & - & 56.9 & 0 \\
\hline 16. O-Methylthiopentanoate & 48.6 & 54.3 & 42.9 & 1.3 \\
\hline 17. Ethylbutanoate & 5.46 & - & 33.8 & 0 \\
\hline 18. O-Ethylselenobutanoate & 85.5 & 13.2 & - & $>>$ \\
\hline 19. Ethyl-4-methylpentanoate & 0.3 & - & 17.9 & 0 \\
\hline $\begin{array}{l}\text { 20. O-Ethyl-4- } \\
\text { methylselenopentanoate }\end{array}$ & 82.3 & 14.5 & - & $>>$ \\
\hline 21. Ethylhexanoate & 2.8 & - & 31.2 & 0 \\
\hline 22. O-Ethylselenohexanoate & 21.4 & 17.8 & - & $>>$ \\
\hline
\end{tabular}


Allyl esters should be considered separately since $\left(\mathrm{M}-\mathrm{CH}_{2} \mathrm{R}^{1}\right)^{+}$ion abundances are specifically affected by the stability of the allyl cation, which they form by further decomposition:

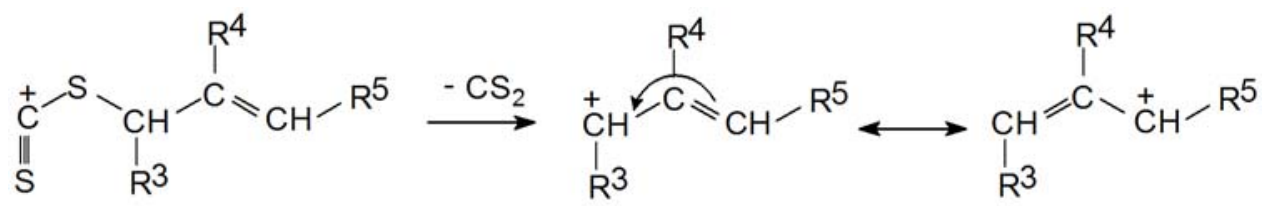

For allyldithiopropanoate, the lack of $\left(\mathrm{M}-\mathrm{CH}_{2} \mathrm{R}^{1}\right)^{+}$is a consequence of the allyl cation stability so that it should not be interpreted as the complete conversion to the enol form. Esters are peculiar molecules among the carbonyl compounds with regard to the possibility of tautomerization of the molecular ion (eqs. 9 and 10). This means that $\left(\mathrm{M}-\mathrm{CH}_{2} \mathrm{R}^{1}\right)^{+}$might have contribution from both tautomers whenever the structure allows the rearrangement and the ion abundances ratio in Table 1 does not reflect the real enol content which should be higher. So that, the ratio value for all compounds would indicate the minimum enol content in the tautomeric equilibrium.
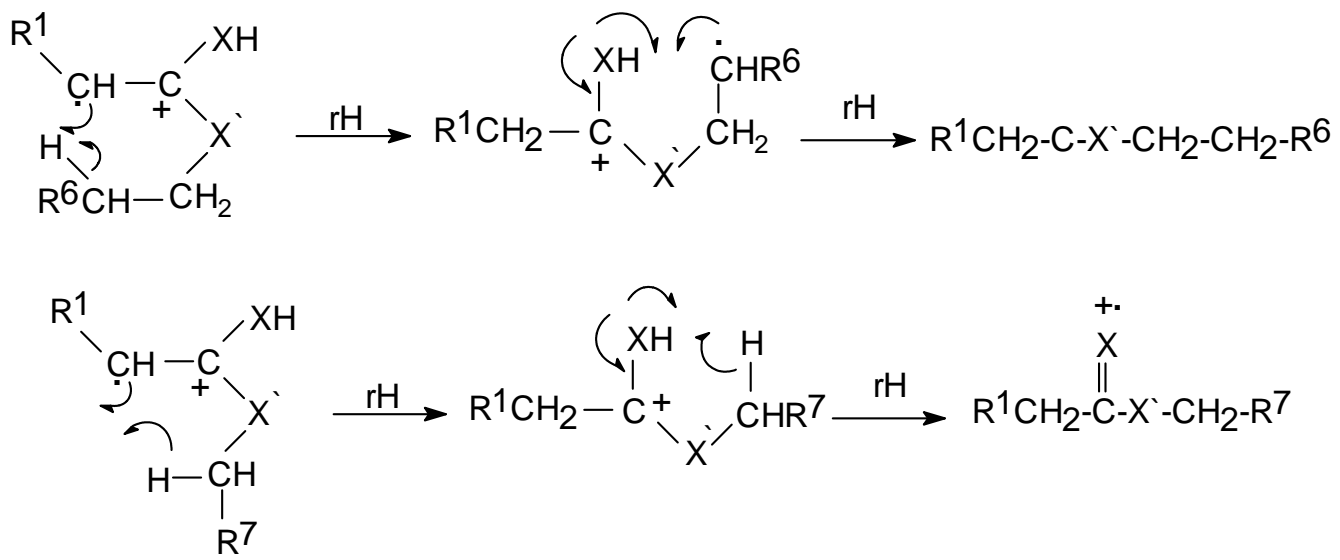

Evidently, among organic compounds families, esters are rather unique in regard to their mass spectra and the use of mass spectrometry data to study their tautomeric equilibria (equation 5), methodology that has been very useful to predict tautomerism occurrence for other compounds families ${ }^{28-36}$. For esters, the spectral interferences have to be considered carefully for the comparison among family members. Notwithstanding, by analyzing Table 1 the enol occurrence is null for oxygenated esters and quite significant for the selected thioesters, particularly with the second exchange in heteroatom (dithio compounds).

When the heteroatom is selenium a strong equilibrium shift towards the enol tautomer is observed, very likely due to its higher tendency to form double bonds ${ }^{23}$.

The effect of the size of $\mathrm{R}^{1}$ on the ratio value correlates qualitatively well with the tendency to shift towards the enol form when $\mathrm{R}^{1}$ increases. From Table 1 this is evident for dithio compounds: 4 vs 7-8 $\left(\mathrm{R}^{1}: \mathrm{H}\right.$ vs $\left.\mathrm{CH}_{3}\right)$ and 2 vs $\mathbf{1 4}\left(\mathrm{R}^{1}: \mathrm{H}\right.$ vs $\left.\mathrm{C}_{2} \mathrm{H}_{5}\right)$. For thio compounds the 
comparisons are: 12 vs $16\left(\mathrm{R}^{1}: \mathrm{CH}_{3}\right.$ vs $\left.\mathrm{C}_{3} \mathrm{H}_{7}\right)$ and $\mathbf{1 2}$ vs $\mathbf{1 0}\left(\mathrm{R}^{1}: \mathrm{CH}_{3}\right.$ vs $\left.\mathrm{C}_{6} \mathrm{H}_{5}\right)$, which ratio values increase consistently.

\section{Theoretical Calculations}

Table 2 shows the differences between the heats of formation of the keto and enol forms for the neutral molecules and radical cations. A reasonable tendency correlation with the mass spectral data is obtained when considering the calculations for the neutral molecules. The lower energy requirement for the enol formation for the thio compounds, which decreases even more for dithio compounds, is also supported by the theoretical calculations.

No tendency is observed between the molecular orbital calculations for the radical cations and the corresponding mass spectral data. The calculations for the oxygenated esters have been omitted with the exception of ethylacetate and ethyl butanoate which, as all their analogues in Table 1, render a high energy value due to their very low relative tendency to enolizate.

The ease of enol formation increases in the order thiocarbonylesters $<$ dithioesters $<$ selenocarbonylesters and it is consistent with the size of $\mathrm{R}^{1}$. These results constitute an additional evidence of tautomerism occurrence for the neutral species disregarding the potential tautomerism that might take place in radical ionic species, which are responsible of the experimental data.

Table 2. Heats of formation difference $\left(\mathrm{kcal} \mathrm{mol}^{-1}\right)$ between the tautomeric forms of esters by AM1 calculations

\begin{tabular}{lcccc}
\hline Compound & $\begin{array}{r}\text { Neutral Molecule } \\
\mathbf{Z} \text { isomer E isomer }\end{array}$ & \multicolumn{2}{c}{$\begin{array}{c}\text { Radical Cation } \\
\mathbf{Z} \text { isomer E isomer }\end{array}$} \\
\hline Ethylacetate & \multicolumn{2}{c}{27.1} & \multicolumn{2}{c}{-22.5} \\
\hline Ethyldithioacetate & \multicolumn{2}{c}{2.5} & \multicolumn{2}{c}{0.64} \\
\hline Allyldithioacetate & \multicolumn{2}{c}{12.5} & -3.9 \\
\hline Allyldithiopropanoate & 8.8 & 8.2 & -26.3 & -25.0 \\
\hline O-Ethylphenylthioacetate & 0.5 & 0.3 & 14.8 & 15.1 \\
\hline O-Propylthiopropanoate & 2.1 & 2.3 & -0.84 & -13.6 \\
\hline Methyldithiobutanoate & -1.6 & -1.5 & 1.6 & 1.4 \\
\hline O-Methylthiopentanoate & -1.05 & 0.9 & -37.2 & -38.5 \\
\hline Ethylbutanoate & 14.6 & 12.7 & -53.5 & -55.6 \\
\hline O-Ethylselenobutanoate & -5.73 & -3.84 & 1.91 & 3.26 \\
\hline O-Ethyl-4- & -7.5 & -5.7 & 9.5 & 13.6 \\
methylselenopentanoate & -2.7 & -14.1 & -7.4 & -0.5 \\
\hline O-Ethylselenohexanoate & -14.4 & & & \\
\hline
\end{tabular}




\section{Conclusions}

There is a remarkable tendency towards enolic structures formation when sulfur replaces oxygen in the esters here reported. This behavior is evidenced not only by mass spectra but also by theoretical calculations and the mutual correlation. These results constitute an evidence of the feasibility of tautomerism evaluation by mass spectrometry since it seems that it reflects adequately tautomeric equilibria between neutral species with negligible influence of tautomeric equilibria between ionic species in the gas phase. It is important to take into consideration that reactivity of radical-ionic species can differ sensibly from the neutral analogues.

The results coming from the application of molecular orbital theory support the spectrometric data and the fact that they correspond to tautomeric equilibria between neutral species, so that, subsequent ionization in the ion source does not affect the position of those equilibria although some influence has been observed for this family of compounds.

\section{References}

1. Toullec, In The Chemistry of Enols, Rappoport, Z. Ed.; Wiley: Chichester, 1990; Chapter 6, p 324.

2. Chiang, Y.; Kresge, A. J. Science 1991, 253, 295.

3. Keeffe, J. R.; Kresge, A. J.; Scheep, N. P. J. Am. Chem. Soc. 1988, 110, 1993.

4. Hart, H.; Rappoport, Z.; Biali, S. E. The Chemistry of Enols, Rappoport, Z. Ed.; Wiley: Chichester, 1990; Chapter 1, pp 1-74

5. (a) Paquer, D. Int. J. Sulfur Chem. B 1972, 7, 269. (b) Ohno, A. In Organic Chemistry of Sulfur, Oae, S. Ed.; Plenum Press: New York, 1977; Chapter 5.

6. Dunn, E. in Comprehensive Organic Chemistry, Barton, D. H. R.; Ollis, W. D. Eds.; Pergamon: New York, 1979; pp 373-487.

7. Paquer, D. Int. J. Sulfur Chem. 1973, 8, 173.

8. Pedersen, S.; Chicheibye, S.; Nilsson, N. H.; Lawesson, S. O. Bull. Soc. Chim. Belg. 1978, $87,223$.

9. Selger, T.; Rappoport, Z. J. Org. Chem. 1996, 61, 5462.

10. Dunn, F. J. Am. Chem. Soc. 1986, 108, 630 and references therein.

11. Kunz, S.; Scheithauer, S.; Bleisch Mayer, R. J. Prakt. Chem. 1970, 312, 426.

12. Schmidt, U.; Heymann, I.; Kabitzke, K. Chem. Ber. 1963, 96, 1478.

13. Mayer, R.; H. Berthold, Z. Chem. 1963, 3, 310.

14. Banks, G. R.; Cohen, D. Proc. Chem. Soc. (London), 1963, 83.

15. Raap, Can. J. Chem. 1968, 46, 2251.

16. Mayer, R.; Scheithauer, S.; Kunz, D. Chem. Ber. 1966, 99, 1393.

17. Saquet, M.; Thillier, A. Bull. Soc. Chim. France 1967, 2841; ibid. 1966, 1582. 
18. Schönberg, L.; Vargha, V.; Kaltschmidst, H. Ber. Deut. Chem. Ges. 1931, 64, 2482; ibid. 1966, 66, 237.

19. Gronowitz, S.; Hoffmann, R. A. Ark. Kem. 1960, 15, 499.

20. Gronowitz, S. S.; Moses, P.; Hörnfeldt, A. B.; Hakansson, R. Ark. Kem. 1961, 17, 237.

21. Jones; Moodie, J. M. Terahedron 1963, 19, 1867.

22. Hörnfeldt, B. Ark. Kem. 1964, 22, 211.

23. Sklenak, S.; Apeloig, Y.; Rappoport, Z. J. Chem. Soc., Perkin Trans 2 2000, 2269.

24. Cava, M. P.; Levinson, I. H. Tetrahedron 1985, 42, 5061.

25. Duus, Comprehensive Organic Chemistry, Pergamon Press: Oxford, 1979, Chapter 11, p 223.

26. Pedersen, B. S.; Scheibye, S.; Nilsson, N. H.; Lawesson, S. O. Bull. Soc. Chim. Belg. 1978, 87, 223.

27. (a) HyperChem ${ }^{\circledR} 6.03$ for Windows Molecular Modeling System, Hypercube, Inc., Gainesville, Florida, 2000. (b) Dewar, M. J. S.; Zoebisch, E. G.; Healy, E. F.; Stewart, J. J. P. J. Am. Chem. Soc. 1985, 107, 3902.

28. Allegretti, P. E.; Schiavoni, M. de las M.; Di Loreto, H. E.; Furlong, J. J. P.; Della Védova, C. O. J. Mol. Struct. 2001, 560, 327.

29. Allegretti, P. E.; Labadie, G. R.; González Sierra, M.; Furlong, J. J. P. Afinidad 2000, LVII, 485, 42.

30. Allegretti, P. E.; Castro, E. A.; Furlong, J. J. P. J. Mol. Struct. (Theochem) 2000, 499, 121.

31. Allegretti, P. E.; Gavernet, L.; Castro, E. A.; Furlong, J. J. P. J. Molec. Struct. (Theochem) 2000, 532(1-3) 139.

32. Allegretti, P. E.; Cánepa, A. S.; Bravo, R. D.; Castro, E. A.; Furlong, J. J. P. Asian J. Spectrosc. 2000, 4, 133.

33. Allegretti, P. E.; Gavernet, L.; Castro, E. A.; Furlong, J. J. P. Asian J. Spectrosc. 2001, 5(2), 63.

34. Allegretti, P. E.; Milazzo, C. B.; Castro, E. A.; Furlong, J. J. P. J. Mol. Struct. (Theochem) 2002, 589-590, 161.

35. Allegretti, P. E.; Cortizo, M. S.; Guzmán, C.; Castro, E. A.; Furlong, J. J. P. AKIVOC 2003, $(x), 24$.

36. Allegretti, P. E.; Peroncini, V.; Castro, E. A.; Furlong, J. J. P. Int. J. Chem. Sci. 2003, 1(1), 1. 